\title{
ANALISIS REGRESI LOGISTIK ORDINAL MENGENAI FAKTOR-FAKTOR YANG MEMPENGARUHI TINGKAT PENDIKAN ANAK DI DESA SAYANG - SAYANG
}

\author{
Baiq Dewi Kusuma Ananda ${ }^{1}$, Zulmi Insani ${ }^{2}$, Baiq Rika Ayu Febrilia ${ }^{3 *}$, Dwi \\ Utami Setyawati ${ }^{4}$ \\ 1,2,3,4 Universitas Pendidikan Mandalika \\ Email:11kusuma2780@gmail.com , ${ }^{2}$ zulmiinsani4@gmail.com , ${ }^{3}$ rikafebrilia@ikipmataram.ac.id, \\ ${ }^{3}$ utamiwi.25@gmail.com \\ *Penulis Korespondensi
}

\begin{abstract}
The economic condition of the parents and their level of education are the determining factors for the level of education of the children. The purpose of this study was to analyze the factors affecting the level of education of children (socioeconomic status of parents and parents' latest education). The subjects in this study were 100 people of Sayang-Sayang Village who were determined by simple random sampling technique. Data collection was carried out online using a survey sheet or questionnaire developed with the help of Google Form. The method in analyzing this causal relationship uses ordinal logistic regression analysis. The results showed that the ordinal logistic regression analysis provided two logit models, in which socioeconomic status had a significant effect on the child's education level, while the parents' last education level did not have a significant effect on the child's education level. The first logit model is a logit model that explains the causal relationship between socioeconomic status and the last level of education of high-category children, while the second model is for the middle category level. Research is expected to be one of the references both in the use of ordinal logistic regression and in observing the factors that affect the level of children's education.
\end{abstract}

Keywords: Ordinal logistics regression, factors, level of children's education

\begin{abstract}
Abstrak. Kondisi ekonomi orang tua dan tingkatan pendidikannya menjadi faktor penentu tinggi rendahnya pendidikan anak. Tujuan penelitian ini adalah untuk menganalisis faktor-faktor yang mempengaruhi tingkat pendidikan anak (status sosial ekonomi orang tua dan pendidikan terakhir orang tua). Subjek dalam penelitian ini adalah masyarakat Desa Sayang-Sayang sebanyak 100 orang yang ditentukan dengan teknik sampel acak sederhana. Pengumpulan data dilakukan secara online dengan menggunakan lembar survei atau angket yang dikembangkan dengan bantuan Google Form. Metode dalam menganalisis hubungan sebab akibat ini menggunakan analisis regresi logistik ordinal. Hasil penelitian menunjukkan bahwa analisis regresi logistik ordinal memberikan dua model logit, yang mana status sosial ekonomi berpengaruh signifikan terhadap tingkat pendidikan anak, sedangkan tingkat pendidikan terakhir orang tua tidak berpengaruh signifikan terhadap tingkat pendididkan anak. Model logit petama adalah model logit yang menjelaskan hubungan sebab akibat antara status sosial ekonomi dengan tingkat pendidikan terakhir anak kategori tinggi, sedangkan model kedua untuk tingkat
\end{abstract}


kategori menengah. Penelitian diharapkan menjadi salah satu referensi baik dalam penggunaan regresi logistik ordinal maupun dalam mengamati faktor-faktor yangmempengaruhi tingkat pendidikan anak.

Kata Kunci: Regresi logistik ordinal, factor, tingkat pendidikan anak

\section{PENDAHULUAN}

Pendidikan adalah salah satu wadah pembentukan generasi muda yang maju, cerdas, dan sejahtera. Pendidikan memiliki peranan penting dalam mempersiapkan peserta didik di masa depan sehingga mampu diandalkan oleh masyarakat di masa depan [1]. Terdapat dua faktor yang mempengaruhi keberhasilan pendidikan, di antaranya faktor internal dan faktor eksternal. Faktor eksternal terdiri dari lingkungan sedangkan faktor internal terdiri keluarga dan orang tua. Orang tua memiliki tanggung jawab atas pendidikan anaknya. Menurut [2], untuk memenuhi kebutuhan pendidikan seorang anak adalah tugas dari orang tua. Akan tetapi, kondisi ekonomi orang tua menjadi faktor penentu tinggi rendahnya pendidikan anak. Hal ini sejalan dengan [3] menyatakan bahwa tingkat pendidikan seorang anak dipengaruhi oleh hasil pendapatan orang tua karena status sosial ekonomi masing-masing orang itu berbeda dan memiliki kelas masing-masing, ada yang berada pada kelas tinggi, sedang dan rendah.

Anak-anak yang memiliki latar belakang ekonomi menengah ke atas akan mendapatkan banyak pengetahuan dan arahan mengenai pendidikan untuk masa depannya. Anak-anak yang berstatus ekonomi rendah akan kesulitan mendapatkan informasi dan arahan mengenai pendidikan untuk masa depannya [4]. Anak-anak dengan kondisi ekonomi rendah akan mendapatkan informasi yang terbatas dari orang tua mengenai pendidikan untuk masa depannya, karena orang tuanya lebih memfokuskan untuk memenuhi kebutuhan hidup seharihari. Tinggi rendahnya status ekonomi keluarga memberikan pengaruh yang besar terhadap tingkat pendidikan anak, karena anak membutuhkan biaya untuk memenuhi kebutuhan dalam menyelesaikan pendidikannya [5].

Tidak hanya latar belakang ekonomi, status ekonomi dan pendidikan terakhir orang tua sangat berpengaruh terhadap pendidikan,. Hal ini sejalan dengan [6] yang menyatakan bahwa pendidikan merupakan perihal yang penting, namun hal tersebut dipengaruhi oleh status ekonomi, tingkat pendidikan dan budaya pada suatu daerah. Orang tua yang memiliki tingkat pendidikan yang tinggi dan pengetahuan yang cukup luas akan mempengaruhi sikap kepemimpinannya di dalam keluarga, maka orang tua yang memiliki tingkat pendidikan yang tinggi akan bertambah luas pengetahuan dan pengalaman dalam menata keluarganya [7]. Dengan demikian, orang tua dengan tingkat pendidikan yang tinggi dapat mengarahkan anaknya untuk memiliki tingkat pendidikan yang tinggi pula.

Berkaitan dengan analisis faktor yang mempengaruhi tingkat pendidikan anak, salah satu analisis yang digunakan adalah analisis regresi logistik ordinal. Regresi logistik ordinal adalah perpanjangan dari regresi multinomial [8]. Analisis regresi logistik dinamai sesuai dengan struktur variabel dependen yang mana pada variabel tersebut transformasi logit diterapkan [9]. Pada dasarnya, ada dua kategori umum dari model regresi, yaitu model regresi linier dan model regresi logistik yang mana keputusan untuk memilih regresi linier atau regresi logistik bergantung pada skala pengukuran variabel dependen [10]. Pendapat lain menyatakan bahwa regresi sendiri memiliki banyak model yang mana model yang memiliki 
variabel dependen kategoris bernama regresi logistik sedangkan untuk variabel respon ordinal dengan urutan bernama regresi logistik ordinal [11]. Regresi logistik ordinal digunakan untuk menganalisis hubungan antara variabel respon dan variabel prediktor, di mana variabel respon memiliki karakter polikotomous dengan skala ordinal [12] [13][14]. Lebih jauh, [15] menjelaskan bahwa variabel prediktor dapat berupa kategori, interval atau suatu variabel skala rasio. Regresi logistik ordinal akan menghasilkan model logit [16] yang merupakan log peluang (odds) terjadinya suatu peristiwa [15]. Rasio peluang (odds ratio) untuk setiap prediktor dianggap konstan di semua kemungkinan variabel respon. Dalam model regresi logistik ordinal terdapat asumsi penting yang termasuk dalam odds ordinal. Menurut [17], parameter asumsi ini tidak boleh berubah untuk kategori yang berbeda. Ketika asumsi yang dapat diuji terpenuhi, rasio peluang dalam model logit kumulatif diinterpretasikan sebagai peluang menjadi "lebih rendah" atau "lebih tinggi" pada variabel respon.

Berdasarkan uraian di atas maka yang menjadi tujuan dari penelitian ini adalah untuk menganalisis mengenai regresi logistik ordinal faktor-faktor yang mempengaruhi tingkat pendidikan anak pada masyarakat Desa Sayang-Sayang. Penelitian menitikberatkan pada pengamatan dari sisi sosial ekonomi dan pendidikan terakhir orang tua. Penelitian ini diharapkan dapat menjadi salah satu bahan referensi dalam penggunaan regresi logistik ordinal dan tambahan wawasan mengenai faktor yang mempengaruhi tingkat pendidikan anak.

\section{METODE}

Jenis penelitian yang digunakan dalam penelitian ini adalah penelitian kuntitatif. Data yang digunakan dalam penelitian ini merupakan data primer yang diambil secara langsung melalui 100 orang masyarakat Desa Sayang-Sayang Kecamatan Cakranegara, Kota Mataram, Provinsi Nusa Tenggara Barat (NTB) sebagai subjek penelitian. Sebaran jenis kelamin dari 100 responden adalah 48 perempuan dan 52 laki-laki. Pemilihan sampel diambil menggunakan teknik sampel acak sederhana. Data yang dikumpulkan adalah data penghasilan orang tua per bulan sebagai data sosial ekonomi orang tua, pendidikan terakhir orang tua, dan tingkat pendidikan anak. Setiap responden atau sampel mengisi data menggunakan lembar survei online yang dikembangkan dari aplikasi Google Form. Masingmasing data yang dikumpulkan berperan sebagai variabel respon dan prediktor seperti yang diuraikan berikut.

Variabel $\mathrm{Y}$ adalah data tingkat pendidikan terakhir anak yang dikategorikan menjadi tiga, yaitu

1. Tinggi, untuk tingkat pendidikan Diploma, $\mathrm{S} 1, \mathrm{~S} 2, \mathrm{~S} 3\left(\mathrm{Y}_{1}\right)$

2. Menengah, untuk tingkat pendidikan SMA/SMK/MA sederajat $\left(\mathrm{Y}_{2}\right)$

3. Dasar, untuk tingkat pendidikan SMP/MTs, $\mathrm{SD}$, tidak sekolah $\left(\mathrm{Y}_{3}\right)$

Variabel X1 yang digunakan adalah status sosial ekonomi dengan 3 kategori yaitu :

1. Tinggi, untuk penghasilan orang tua per bulan yang lebih dari 3 juta rupiah $\left(\mathrm{X}_{1,1}\right)$

2. Sedang, untuk penghasilan orang tua per bulan di antara $\mathrm{Rp} 1.500 .00-\mathrm{Rp} 3.000 .000$ $\left(\mathrm{X}_{1,2}\right)$

3. Rendah, untuk penghasilan orang tua per bulan di antara $\mathrm{Rp} 0-\mathrm{Rp} 1.500 .000\left(\mathrm{X}_{1,3}\right)$ 
Variabel X2 adalah data tingkat pendidikan terakhir orang tua dengan kategori yang sama dengan kategori Y.

1. Tinggi, untuk tingkat pendidikan Diploma, S1, S2, S3 $\left(\mathrm{X}_{2,1}\right)$

2. Menengah, untuk tingkat pendidikan SMA/SMK/MA sederajat $\left(\mathrm{X}_{2,2}\right)$

3. Dasar, untuk tingkat pendidikan SMP/MTs, $\mathrm{SD}$, tidak sekolah $\left(\mathrm{X}_{2,3}\right)$

Analisis dengan menggunakan model regresi logistik ordinal dibantu oleh software SPSS dan hasil analisisnya memuat beberapa tabel yaitu tabel deskriptif, tabel kesesuaian model, tabel uji keseluruhan model dan tabel estimasi parameter. Penelitian ini terdiri dari beberapa langkah. Langkah pertama adalah membuat tabel sebaran tingkat pendidikan anak dan tabel tabulasi silang untuk menganalisis karakteristik tingkat pendidikan dari 100 responden berdasarkan setiap variable prediktornya kemudian memberikan interpretasinya. Langkah kedua adalah menguji kesesuaian model dengan menggunakan selang kepercayaan 95\%. Dengan kata lain, nilai taraf signifikansi yang akan menjadi pembanding adalah $5 \%$ atau 0,05 . Hipotesis yang digunakan adalah sebagai berikut.

$\mathrm{H}_{0}$ : Model sesuai

$\mathrm{H}_{1}$ : Model tidak sesuai

$\mathrm{H}_{0}$ akan diterima apabila nilai signifikansi dari Deviance lebih dari 0,05 dan apabila yang terjadi malah sebaliknya, maka $\mathrm{H}_{0}$ akan ditolak. Nilai deviance disini digunakan untuk menguji kecocokan model (goodness of fit) [18][10]. Langkah ketiga adalah melakukan uji model secara menyeluruh yang lebih menekankan pada pengujian konstanta model dengan menggunakan hipotesis berikut.

$\mathrm{H}_{0}: \alpha_{1}=\alpha_{1}=0$

$\mathrm{H}_{1}$ : Minimal ada satu $\alpha_{\mathrm{k}} \neq 0, \mathrm{k}=1,2$

Apabila nilai signifikansi menyeluruh kurang dari 0,05 maka keputusannya adalah $\mathrm{H}_{0}$ ditolak atau dengan kata lain terdapat minimal satu parameter yang signifikan sehingga perlu dilanjutkan pada pengujian secara parsial. Langkah keempat adalah pengujian setiap parameter model atau uji parsial, dengan menggunakan hipotesis:

$$
\begin{aligned}
& \mathrm{H}_{0}: \alpha_{\mathrm{s}}=0 \\
& \mathrm{H}_{1}: \alpha_{\mathrm{s}} \neq 0, \mathrm{~s}=1,2 .
\end{aligned}
$$

Nilai signifikansi variabel yang kurang dari 0,05 akan mendorong kepada keputusan $\mathrm{H}_{0}$ ditolak. Banyaknya model logit dilihat melalui banyaknya konstanta yang muncul dan model ini juga dipengaruhi oleh setiap nilai parameter yang memiliki nilai signifikansi < 0,05 [19]. Model logit yang dihasilkan mengikuti formulasi berikut [15].

$$
\operatorname{logit}(P[Y \leq r \mid x])=\alpha_{0 r}+\sum_{s=1}^{t} \alpha_{s} x_{i s}
$$




\section{HASIL DAN PEMBAHASAN}

Berdasarkan hasil analisis data, diperoleh informasi bahwa tingkat pendidikan dari 100 responden mengikuti pola seperti pada Tabel 1 yang mana $42 \%$ dari responden memiliki tingkat pendidikan Diploma/S1, 46\% memiliki tingkat pendidikan SMA/SMK/MA sederajat dan 12\% memiliki tingkat pendidikan hingga SMP/MTs, SD dan tidak sekolah.

Tabel 1. Sebaran tingkat pendidikan anak

\begin{tabular}{cccc}
\hline No & Tingkat Pendidikan Anak & Frekuensi & Kategori \\
\hline 1 & Diploma/S1 & $42(42 \%)$ & Tinggi \\
\hline 2 & SMA/SMK/MA sederajat & $46(46 \%)$ & Menengah \\
\hline 3 & SMP/MTs, SD, tidak sekolah & $12(12 \%)$ & Dasar \\
\hline
\end{tabular}

Jika ditinjau dari status sosial ekonomi orang tua, maka karakteristik tingkat pendidikan anak mengikuti sebaran pada Tabel 2.

Tabel 2. Karakteristik tingkat pendidikan anak berdasarkan status sosial ekonomi orang tua

\begin{tabular}{ccccc}
\hline \multirow{2}{*}{$\mathrm{X}_{1}$} & \multicolumn{3}{c}{$\mathrm{Y}$} \\
\cline { 2 - 5 } & Tinggi & Menengah & Dasar & Total \\
\hline Tinggi: >3 juta rupiah & $13(59,1 \%)$ & $8(36,4 \%)$ & $1(4,5 \%)$ & $22(100 \%)$ \\
\hline Sedang: Rp 1.500.000 - Rp & $18(48,6 \%)$ & $18(48,6 \%)$ & $1(2,8 \%)$ & $37(100 \%)$ \\
3.000.000 & & & & \\
\hline Rendah: Rp 0 - Rp 1.500.000 & $11(26,8 \%)$ & $20(48,7 \%)$ & $10(24,4 \%)$ & $41(100 \%)$ \\
\hline
\end{tabular}

Tabel 2 menunjukkan besar penghasilan orang tua untuk mengukur status sosial ekonomi karena status sosial ekonomi adalah latar belakang ekonomi keluarga atau orang tua yang diukur dengan tingkat pendidikan, tingkat pendapatan, pemilikan kekayaan, atau fasilitas serta jenis pekerjaan [20]. Pada tabel tersebut diperoleh informasi bahwa status sosial ekonomi masyarakat Desa Sayang-Sayang berada pada level sedang dan rendah. Selain itu, kuantitas terbesar dari anak yang hanya memiliki tingkat pendidikan sampai pada SMP/MTs, SD bahkan yang tidak sekolah memiliki status sosial ekonomi orang tua dalam kategori rendah. Dari sini terlihat bahwa status sosial ekonomi orang tua sangat mempengaruhi tingkat pendidikan anak karena untuk mencapai atau menyelesaikan tingkat pendidikan yang tinggi dibutuhkan biaya yang tinggi pula.

Berkaitan dengan tingkat pendidikan orang tua, karakteristik dari tingkat pendidikan anak ditunjukkan oleh Tabel 3.

Tabel 3. Karakteristik tingkat pendidikan anak berdasarkan pendidikan terakhir orang tua

\begin{tabular}{ccccc}
\hline \multirow{2}{*}{$\mathrm{X}_{2}$} & \multicolumn{3}{c}{$\mathrm{Y}$} \\
\cline { 2 - 5 } & Tinggi & Menengah & Dasar & Total \\
\hline Tinggi & $6(75 \%)$ & $2(25 \%)$ & $0(0 \%)$ & $8(100 \%)$ \\
\hline Menengah & $15(51,8 \%)$ & $14(48,2 \%)$ & $0(0 \%)$ & $29(100 \%)$ \\
\hline Dasar & $21(33,3 \%)$ & $29(46 \%)$ & $13(20,7 \%)$ & $63(100 \%)$ \\
\hline
\end{tabular}


Tabel 3 menginformasikan bahwa tingkat pendidikan orang tua di Desa Sayang-sayang didominasi oleh pendidikan tingkat menengah dan dasar. Lebih jauh dapat diamati pula bahwa Hanya orang tua dengan tingkat pendidikan hingga SMP/MTs, SD dan tidak sekolah yang memiliki anak dengan tingkat pendidikan pada kategori rendah. Hal itu dikarenakan orang tua dengan tingkat pendidikan yang rendah tidak memiliki pengetahuan yang cukup luas mengenai pendidikan untuk anak-anaknya, sehingga anak-anaknya juga tidak memiliki kemauan atau minat yang tinggi untuk mengejar atau mencapai tingkat pendidikan yang tinggi. Tingkat pendidikan orang tua yang rendah cenderung memiliki pengetahuan yang sempit terhadap pendidikan. Mereka beranggapan bahwa lulus dengan kategori dasar dirasa sudah cukup. Hal ini berbeda dengan pemikiran orang tua dengsn tingkat pendidikan dalam kategori tinggi yang pengetahuannya lebih luas mengenai pendidikan anak [21]. Dukungan, perhatian, pengetahuan, dan pengalaman yang diberikan orang tua memiliki pengaruh yang sangat besar bagi masa depan seorang anak.

Untuk melihat lebih jauh mengenai hasil analisis regresi logistik ordinal antara tingkat pendidikan anak, tingkat pendidikan orang tua dan status sosial ekonomi orang tua, maka tahapan berikutnya adalah melihat bagaimana kesesuaian model yang diperoleh dari data survei dengan model regresi logistik ordinal. Uji kesesuaian model ini mengikuti hipotesis $\mathrm{H}_{0}$ : model sesuai dan $\mathrm{H}_{1}$ : model tidak sesuai. Hasil pengujiannya disajikan pada Tabel 4.

Tabel 4. Uji kesesuaian model

\begin{tabular}{ccccc}
\hline & $\begin{array}{c}\text { Chi- } \\
\text { Square }\end{array}$ & $\begin{array}{c}\text { Derajat } \\
\text { Bebas }\end{array}$ & $\begin{array}{c}\text { Nilai } \\
\text { Signifikansi }\end{array}$ & Keputusan \\
\hline Deviance & 12.810 & 12 & 0,383 & $\mathrm{H}_{0}$ diterima \\
\hline
\end{tabular}

Tabel 4 menunjukkan bahwa nilai signifikansi dari model yang diuji adalah 0,383 yang mana nilai ini kurang dari nilai $\mathrm{P}$ yang digunakan, yaitu 0,05. Dengan demikian dapat disimpulkan bahwa model yang diperoleh dari data survei sudah sesuai dengan model regresi logistik ordinal. Tahap berikutnya adalah menganalisis parameter yanag dihasilkan model secara menyeluruh [11]. Tes ini dilakukan dengan menggunakan Uji -2log likelihood atau juga dikenal sebagai Uji Rasio Kemungkinan (Likelihood Ratio). Hasil analisis ditunjukkan pada Tabel 5 dan hipotesis yang digunakan sebagai dasar adalah sebagai berikut.

Tabel 5. Uji keseluruhan model menggunakan likelihood ratio

\begin{tabular}{cccccc}
\hline Model & $\begin{array}{c}-2 \text { Log } \\
\text { Likelihood }\end{array}$ & Chi-Square & $\begin{array}{c}\text { Derajat } \\
\text { Bebas }\end{array}$ & $\begin{array}{c}\text { Nilai } \\
\text { Signifikansi }\end{array}$ & Keputusan \\
\hline Intercept Only & 56,742 & & & & \\
\hline Final & 40,703 & 16,039 & 4 & 0,003 & $\mathrm{H}_{0}$ diolak \\
\hline
\end{tabular}

Pengujian pada tabel 5 menggunakan hipotesis berikut

$\mathrm{H}_{0}: \alpha_{1}=\alpha_{1}=0$

$\mathrm{H}_{1}$ : Minimal ada satu $\alpha_{k} \neq 0, k=1,2$

Fokus dari pengujian yang hasilnya disajikan pada Tabel 5 adalah menguji nilai konstanta 1 dan 2 yang diperoleh dari model (lihat Tabel 6). Berdasarkan Tabel 5 diperoleh informasi 
bahwa nilai signifikansi $=0,003<0,05$ dan dapat disimpulkan bahwa nilai parameter yang diperoleh (konstanta 1 dan 2) signifikan untuk model regresi logistik ordinal.

Tabel 6. Parameter hasil estimasi

\begin{tabular}{|c|c|c|c|c|c|}
\hline Variabel & Kategori & $\begin{array}{c}\text { Nilai } \\
\text { Parameter } \\
(\alpha)\end{array}$ & $\begin{array}{c}\text { Estimasi } \\
\text { Standar } \\
\text { Eror }\end{array}$ & $\begin{array}{l}\operatorname{Exp} \\
(\alpha)\end{array}$ & $\begin{array}{c}\text { Nilai } \\
\text { Signifikansi }\end{array}$ \\
\hline $\begin{array}{c}\text { Tingkat } \\
\text { Pendidikan }\end{array}$ & $\begin{array}{c}\text { Konstanta } 1 \\
\left(Y_{1}\right)\end{array}$ & $-1,408$ & 0,362 & & 0,000 \\
\hline Anak (Y) & $\begin{array}{c}\text { Konstanta } 2 \\
\left(Y_{2}\right)\end{array}$ & 1,192 & 0,355 & & 0,001 \\
\hline Status & Tinggi $\left(X_{1,1}\right)$ & $-1,262$ & 0,569 & 0,28 & 0,026 \\
\hline Sosial & Sedang $\left(X_{1,2}\right)$ & $-1,045$ & 0,471 & 0,35 & 0,027 \\
\hline $\begin{array}{l}\text { Ekonomi } \\
\text { Orang Tua } \\
\left(\mathrm{X}_{1}\right)\end{array}$ & Rendah & 0 & . & . & . \\
\hline Pendidikan & Tinggi $\left(X_{2,1}\right)$ & $-1,167$ & 0,786 & 0,31 & 0,137 \\
\hline $\begin{array}{l}\text { Terakhir } \\
\text { Orang Tua } \\
\left(\mathrm{X}_{2}\right)\end{array}$ & $\begin{array}{c}\text { Menengah } \\
\left(X_{2,2}\right)\end{array}$ & $-0,802$ & 0,475 & 0,45 & 0,091 \\
\hline & Dasar & 0 & & & \\
\hline
\end{tabular}

Tabel 6 menyajikan nilai konstanta dan koefisien dari setiap variabel dalam model. Pada tabel tersebut terdapat dua konstanta model yang menunjukkan adanya dua variabel respon pada model regresi logistik ordinal [22]. Hal ini mengindikasikan adanya dua model logit yang akan diperoleh. Melalui tabel ini diperoleh juga informasi mengenai hasil pengujian secara parsial mengenai setiap nilai koefisien dari parameternya. Hipotesis pengujian mengacu pada hipotesis berikut:

$$
\begin{aligned}
& \mathrm{H}_{0}: \boldsymbol{\alpha}_{\boldsymbol{s}}=\mathbf{0} \\
& \mathrm{H}_{1}: \alpha_{s} \neq 0, s=1,2 .
\end{aligned}
$$

Oleh karena nilai signifikansi dari variabel $\left(\boldsymbol{X}_{\mathbf{1}, \mathbf{1}}\right)$ dan $\left(\boldsymbol{X}_{\mathbf{1}, \mathbf{2}}\right)$ kurang dari 0,05 maka keputusan yang diambil adalah menolak $\mathrm{H} 0$ atau dengan kata lain nilai parameter ini yang signifikan. Dua nilai parameter lainnya tidak signifikan. Berdasarkan uraian ini, maka model logit yang diperoleh adalah

$$
\begin{gathered}
\operatorname{logit}\left(\boldsymbol{Y}_{\mathbf{1}}\right)=\log \left(\frac{\boldsymbol{Y}_{\mathbf{1}}}{\mathbf{1}-\boldsymbol{Y}_{\mathbf{1}}}\right)=-\mathbf{1 , 4 0 8}+\left(-\mathbf{1}, \mathbf{2 6 2} \boldsymbol{X}_{\mathbf{1 , 1}}\right)+\left(-\mathbf{1 , 0 4 5} \boldsymbol{X}_{\mathbf{1 , 2}}\right) \\
\operatorname{logit}\left(Y_{2}\right)=\log \left(\frac{Y_{2}}{1-Y_{2}}\right)=1,192+\left(-1,262 X_{1,1}\right)+\left(-1,045 X_{1,2}\right) .
\end{gathered}
$$

Bentuk logit di atas digunakan untuk menentukan peringkat kepentingan relatif dari variabel respon [19]. Dalam model logit tersebut memperoleh hasil bahwa status sosial ekonomi orang tua berpengaruh signifikan terhadap tingkat pendidikan anak dibandingkan dengan pendidikan terakhir orang tua. Model logit pertama mengindikasikan hubungan antara variabel tingkat pendidikan terakhir anak kategori tinggi dengan variabel status sosial 
ekonomi kategori tinggi dan sedang, sedangkan model kedua menjelaskan hubungan antara variabel tingkat pendidikan terakhir anak kategori sedang dengan variabel status sosial ekonomi kategori yang sama. Interpretasi model logit yang diperoleh menggunakan nilai Exp $(\alpha)$ pada Tabel 6 yang juga disebut sebagai odds ratio. Berdasarkan Tabel 6, nilai eksponensial dari nilai parameter variabel status sosial ekonomi orang tua kategori sedang lebih besar dari kategori tinggi. Ini berarti anak-anak di Desa Sayang-sayang yang status sosial ekonomi orang tuanya sedang lebih memiliki peluang untuk melanjutkan pendidikan ke tingkat yang lebih tinggi dibandingkan anak-anak yang status sosial ekonomi orang tuanya termasuk dalam kategori tinggi.

\section{KESIMPULAN}

Berdasarkan hasil penelitian dan pembahasan di atas maka dapat disimpulkan bahwa melalui analisis regresi logistik ordinal, faktor yang mempengaruhi tingkat pendidikan anak di Desa Sayang-Sayang adalah status sosial ekonomi orang tua, yang diwakili oleh besarnya penghasilan orang tua. Dalam model ini, faktor tingkat pendidikan terakhir orang tua tidak berpengaruh secara signifikan. Secara umum diperoleh bahwa tingkat pendidikan anak masyarakat Desa Sayang-Sayang berada dalam kategori tinggi walaupun status ekonomi orang tuanya lebih banyak berada pada level sedang dan rendah.

\section{REFERENSI}

[1] N. P. Suciningrum and E. S. Rahayu, "Pengaruh Status Sosial Ekonomi Orang Tua dan Motivasi Belajar Terhadap Minat Melanjutkan Studi ke Perguruan Tinggi pada Kelas XI di SMA Pusaka 1 Jakarta," J. Pendidik. Ekon. dan Bisnis, vol. 3, no. 1, pp. 1-21, 2015.

[2] D. Areva, "Pengaruh Status Sosial Ekonomi Orang Tua dan Motivasi Orang Tua Terhadap Tingkat Pendidikan Anak Pedagang Toko/Kios di Pasar Raya Kota Padang," Econ. J. Econ. Econ. Educ., vol. 4, no. 1, pp. 52-60, 2015.

[3] Fitrianingsih, B. Genjik S., and R. Rosyid, "Pengaruh Pendapatan Orang Tua Terhadap Tingkat Pendidikan Anak Desa Sungai Asam Kabupaten Kubu Raya," J. Pendidik. dan Pembelajaran, vol. 5, no. 5, pp. 1-11, 2016.

[4] S. Nurhayati, "Pengaruh Kondisi Ekonomi Terhadap Tingkat Pendidikan Anak di Desa Sinar Tebudak Kecamatan Tujuh Belas," Pendidik. dan Pembelajaran, vol. 6, no. 7, pp. 1-8, 2017.

[5] M. Z. Abdullah, T. S. Putro, and Syapsan, "Pengaruh Kondisi Sosial Ekonomi Terhadap Tingkat Pendidikan Anak Nelayan di Desa Bekawan Kecamatan Mandah Kabupaten Indragiri Hilir," J. Ekon., vol. 25, no. September, pp. 71-84, 2017.

[6] B. Saputra and Y. Suasti, "Aspirasi Orang Tua Tentang Pendidikan Anak," J. Buana, vol. 3, no. 1, pp. 7-14, 2019.

[7] A. C. J. Emor, A. L. Lonto, and T. Pangalila, "Pengaruh Tingkat Pendidikan Orang Tua Terhadap Pendidikan Anak di Kelurahan Pinasungkulan Kecamatan Ranowulu Kota Bitung," J. Civ. Educ., vol. 3, no. 1, pp. 45-57, 2019.

[8] P. Lu, H. Wang, and D. Tolliver, "Prediction of Bridge Component Ratings Using Ordinal Logistic Regression Model,” Math. Probl. Eng., vol. 2019, pp. 1-11, 2019.

[9] E. Bozpolat, "Investigation of the self-regulated learning strategies of students from the faculty of education using ordinal logistic regression analysis," Kuram ve 
Uygulamada Egit. Bilim., vol. 16, no. 1, pp. 301-318, 2016.

[10] A. Larasati, C. DeYong, and L. Slevitch, "Comparing Neural Network and Ordinal Logistic Regression to Analyze Attitude Responses," Serv. Sci., vol. 3, no. 4, pp. 304312, 2020.

[11] D. R. S. Saputro and P. Widyaningsih, "Limited memory Broyden-Fletcher-GoldfarbShanno (L-BFGS) method for the parameter estimation on geographically weighted ordinal logistic regression model (GWOLR)," AIP Conf. Proc., vol. 18, no. 68, pp. 040009-1-040009-9, 2017.

[12] M. Nusrang, R. Bakri, A. S. Ahmad, and Asfar, "Analisis Regresi Logistik Ordinal Terhadap Faktor-Faktor yang Mempengaruhi Predikat Kelulusan Mahasiswa S1 Universitas Negeri Makasar," in Prosiding Seminar Nasional Lembaga Penelitian UNM, 2017, vol. 2, no. 1, pp. 655-661.

[13] F. M. Ali et al., "Mapping of the DLQI scores to EQ-5D utility values using ordinal logistic regression," Qual. Life Res., vol. 26, no. 11, pp. 3025-3034, 2017.

[14] V. F. Rochmah, “Analisis Faktor-Faktor yang Mempengaruhi Keberhasilan Nilai Raport Siswa SMP Kyai Hasyim Surabaya dengan Menggunakan Metode Regresi Logistik Ordinal," Institut Teknologi Sepuluh November, 2017.

[15] A. O. Adejumo and A. A. Adetunji, "Application of Ordinal Logistic Regression in the Study of Students' Performance," Math. Theory Model., vol. 3, no. 11, pp. 10-19, 2013.

[16] V. Singh, S. N. Dwivedi, and S. V. S. Deo, "Ordinal logistic regression model describing factors associated with extent of nodal involvement in oral cancer patients and its prospective validation," BMC Med. Res. Methodol., vol. 20, no. 1, pp. 1-8, 2020.

[17] E. Ari and Z. Yildiz, "Paralel Lines Assumption in Ordinal Logisic Regression and Parallel Lines Assumption in Ordinal Logistic," Int. Interdiscip. J. Sci. Res., vol. 1, no. January 2014, pp. 8-23, 2016.

[18] J. O. Moraes et al., "An ordinal logistic regression approach to predict the variability on biofilm formation stages by five Salmonella enterica strains on polypropylene and glass surfaces as affected by $\mathrm{pH}$, temperature and NaCl," Food Microbiol., vol. 83, no. April, pp. 95-103, 2019.

[19] A. Ghasemzadeh, B. E. Hammit, M. M. Ahmed, and R. K. Young, "Parametric Ordinal Logistic Regression and Non-Parametric Decision Tree Approaches for Assessing the Impact of Weather Conditions on Driver Speed Selection Using Naturalistic Driving Data," Transp. Res. Rec., vol. 2672, no. 12, pp. 137-147, 2018.

[20] R. P. F. Astuti, "Pengaruh Status Sosial Ekonomi dan Life Style Terhadap Perilaku Konsumsi Mahasiswa Jurusan Pendidikan Ekonomi IKIP PGRI Bojonegoro," J. Edutama, vol. 3, no. 2, pp. 49-58, 2016.

[21] A. S. Anjani, S. Dahlan, and S. Mayasari, "Hubungan Tingkat Pendidikan dan Tingkat Penghasilan Orang Tua terhadap Aspirasi Melanjutkan Studi," ALIBKIN (Jurnal Bimbing. Konseling), vol. 7, no. 2, 2019.

[22] H. M. Fenta, D. L. Workie, D. T. Zike, B. W. Taye, and P. K. Swain, "Determinants of stunting among under-five years children in Ethiopia from the 2016 Ethiopia demographic and Health Survey: Application of ordinal logistic regression model using complex sampling designs," Clin. Epidemiol. Glob. Heal., vol. 8, no. 2, pp. 404 413, 2020. 